\title{
The Main Directions of the Humanization of Industrial Objects in Urban Environment
}

\author{
Maksym Votinov, Olga Smirnova, Maria Liubchenko
}

\begin{abstract}
The tendency to transform the old industrial areas began in 1950-1960 last century in Europe and America. By the end of the twentieth century with the development of the world economy, the time has come when the transformation of industrial infrastructure is becoming a comprehensive phenomenon. Currently, in the economies of developed countries, forms of transformation such as global mergers, takeovers, re-equipment and re-functioning are being intensively implemented. Based on the analysis of positive foreign experience, the main directions of humanization of the urban environment are considered through the transformation of industrial facilities. The transformation of industrial facilities and their territories with a change in functionality becomes the main direction of humanization of the urban environment in the XXI century. Numerous architectural and compositional techniques are allowed to adapt any industrial facility in the dynamic infrastructure of the city.
\end{abstract}

Keywords: humanization; renovation; reorganization; revitalization; urban environment

\section{INTRODUCTION}

Processes for the transformation of industrial areas have been arising for a long time. The tendency to transform the old industrial areas began in 1950-1960 in Europe and America, when the old industrial areas within cities with access to highways regained their attractiveness due to lack of free areas in the suburbs, as well as the presence of buildings and infrastructure in the field of point development. By the end of the twentieth century, with the development of the world economy, the time has come when the transformation of industrial infrastructure is becoming a comprehensive phenomenon. Currently, in the economies of developed countries, forms of transformation such as global mergers, takeovers, re-equipment and re-functioning are being intensively implemented.

Production turned out to be neither competitive nor efficient because of socioeconomic problems in the Commonwealth of Independent States. There were also a lot of unexploited industrial facilities and territories have appeared and entailed urban issues that have made the urban anti-humane environment. In these conditions it is necessary to determine the main directions of humanization of the urban environment through the transformation of industrial facilities.

Only certain aesthetic and compositional aspects of industrial facilities forming are considered in research $[1,2$, $3]$.

\subsection{Analysis of the Literature Data and the Formulation of the Problem}

The latest research analysis of publications has shown that the issues of improving the industrial objects architectural environment in the city and various aspects of the urban environment formation are considered in the following research papers of authors:

1) The historical development of industrial architectural objects was considered in the works of Agranovich \& Mamleev [4], Vershinin [5] etc.
2) The typological formation of the architectural environment of production objects was researched by Demidov \& Khrustalev [6], and Votinov [7]. However, the design methods discussed in these works do not cover many of the humanistic aspects of the modern development of industrial objects.

3) Issues of urban planning of industrial objects, their interaction with residential and other areas of cities were considered in their works: Avdotin et al. [8, 9], Savarenskaya [10], Biryukov [11], and Daun [12].

4) Energy saving and ecologization of the urban environment - scientific works of Sullivan \& Krieger [13], Voskresenskiy [14], Côté et al. [15], and Gibson et al. [16].

5) General theoretical studies on the state, current problems, prospects for the development of industrial architecture, including the influence of innovations, were reflected in their works by Vershinin [5], Kim [17], Demidov \& Khrustalev [18], Getun [19], and Semenova [20].

Research of the materials on this matter indicates that the issues of improving the formation of the architecture of production objects is still insufficiently studied. In the ecological crisis, the problem of renovation of industrial areas is transformed into the problem of the discrepancy of the modern urban environment with the ecological and aesthetic requirements of comfort.

Exploring the regulatory documents [21] has shown that their content does not sufficiently reflect the peculiarities of the industrial objects formation with taking into account the growing demands of the population to form functional, environmental and aesthetic comfortable conditions for work and production. Having taken note of this analysis, a holistic methodological approach to the problem of humanization and greening of industrial objects in the urban environment has not appeared, yet. However, a positive experience in solving certain aspects of this problem can be traced in theoretical and design development. 


\subsection{Purpose and Objectives of the Research}

The purpose of the article is to determine the main directions of humanization of the urban environment through the transformation of industrial facilities.

Objectives of the study:

1) To determine the main approaches of the industrial environment humanization with full or partial preservation of their functions.

2) To identify the main directions of the urban environment humanization by the elimination of the industrial function.

\subsection{Research Methodology and Approaches to Optimizing and Greening of Industrial Objects in Urban Environment}

Analysis of the literature data and regulatory documents of the industrial facilities formation in the urban environment made it possible to determine the main methodology and approaches to the research of this problem.

To formulate the research strategy, positions of the system-ecological and environmental approaches were used. They were the methodological basis for the development of scientifically theoretical principles and directions for the industrial facilities humanization in the urban environment.

The system-ecological approach in the solution of townplanning problems assumes consideration of various objects of town-planning activity as human environment elements. It is aimed at improving the formation of the urban environment and preserving the historical basis, developing and enriching its ecological and aesthetic potential, and an optimal solution to contemporary problems in the environment of life. Such an approach to designing urban environment objects is necessary in connection with anthropogenic pollution of the biosphere, since the consumption of natural resources is becoming more and more dangerous.

The environmental approach is a methodology for researching the working environment as a combination of elements: economic (industrial enterprise and production organization), human (worker and their needs), and public (society's attitude to production and its employees). The environmental approach used when researching these objects puts forward certain requirements for their formation and the methods are common in professional architectural practice in such concepts as the objective environment (situational structure of the environment and the functional typology of environmental situations). The environmental approach involves the consideration of environment as a result of a person's mastering their life environment. Accordingly, the activity and behavior of a person are accepted as a determining factor that binds the individual elements of the environment into integrity. The main goal of modern project thinking is the formation principle of the objective and spatial environment as an organic unity of the visual-sensual system and the functional place conditions. The methodology for developing issues of environmental comfort includes:

- Analysis of projects and field surveys of domestic and foreign industrial enterprises and industrial areas located in urban areas in the creating a comfortable working environment aspect;

- The working premises surveys of industrial enterprises specialized for the work of disabled people [22];

- Systematization of factors affecting the working environment comfort level, taking into account the adverse effects of the working environment on people.

The methodology for developing issues of improving the aesthetic quality of the human labor activity environment in industrial enterprises includes:

- Generalization of the scientific research results on the architectural improvement, artistic level of industrial enterprises and the main industries development;

- The concept of industrial enterprise formation and development considering the possible preferences of workers being in a formed technical environment conditions. It is necessary to take into account the trends of shaping in the world industrial architecture formed under the influence of human environmental engineering, the systematization of technical objects outside the architectural and design activities with negative affecting on the architectural level of industrial enterprises development, the analysis of the patterns of formation, directions for improvement industrial objects.

\section{MAIN APPROACHES TO THE HUMANIZATION OF INDUSTRIAL OBJECTS IN THE URBAN ENVIRONMENT}

Industrial construction, performing the city-forming function, actively influences the formation of the cities' architectural appearance. It has an emotional impact on a person, due to its parameters and specific typological characteristics of architectural forms, introduces additional diversity in the architectural composition of streets and squares. Industrial objects with historical and cultural value undoubtedly have a positive emotional impact on a person.

As a rule, these objects have a high level of architectural and artistic qualities. In most cases, these are buildings with carefully designed facades, precisely calibrated in style and proportions, with an already established, interconnected and high-quality environment, to a person-scale. In this regard, such objects always have a positive visual impact on the person.

Industrial facilities that do not function with their destroyed facades and with abandoned areas in the form of landfills become unsafe and have a negative impact on the psycho-physiological state of a person, especially in large and major cities, where they occupy large areas. The researcher of ecological psychology M. Chernoushek writes about the relevance of the problem of researching the influence of the architectural-spatial environment on a person: "While the physical, chemical and biological influence of the environment on a person is relatively well studied and fixed, the psychological influence of the environment on its creator is man, we know much less. Nevertheless, the psychological impact on the person of the environment created by him is significant, despite the fact that we do not even realize it." In perspective, this aspect 
appears to be the key means of humanizing the urban environment [23].

Of great importance for the human perception psychology in the urban environment is the nature of the buildings and structures placement and their large-scale characteristics, color, the preservation level of facades, outdated equipment and technology. This leads to certain contradictions between the man - production - city. Often, such problems are proposed to be solved, eliminating even profitable production. At the same time, the social and economic advantages of the location of industrial facilities in the structure of the city, including direct connection with residential areas, are lost, and the uniqueness of the existing architectural environment is disturbed. Many industrial facilities are an integral part of historic buildings, which are intertwined with the environment. In their own way, they are a naturally formed historical layering environment and continue to exist in a certain abstracted space outside of time.

At the same time, most of the industrial buildings, especially in the central historical part of the city, are monuments of architecture or culture and form the architectural and artistic image of the city. However, since most industrial facilities have not functioned for a long time, under the influence of natural factors, many buildings are dilapidated, and facade decoration elements have been lost. It is also very important to note the compositional and artistic features of industrial buildings. The architectural, artistic, and aesthetic qualities of many industrial buildings are low as a result of unacceptable excessive subordination of architectural issues to technical tasks and limited search for new ways to achieve architectural expressiveness. A natural and actual problem arises: the need to transform the industrial zones of cities into modern conditions and the needs of society. This process does not involve the destruction of an already established organism: it implies a change and transformation of its infrastructure.

There are three main approaches to the transformation of industrial facilities and their territories in order to humanize the urban environment (Fig. 1):

1) With full preservation of the production function;

2) With partial preservation of the production function;

3) With the elimination of the production function.

In order to humanize the industrial infrastructure, it is necessary to improve the formation of industrial enterprises and their territories while maintaining the production function through reorganization, reconstruction, restoration, adaptation, and modernization.

Reorganization is the transformation of the organizational structure and management structure of the enterprise while maintaining fixed assets and production potential of the facilities. The term "reorganization" has several meanings depending on the scope of application. In this context, it is a kind of radical complex innovation, which is the restructuring of the object's organizational structure (system, goals, relationships, and norms). The reorganization of industrial buildings and structures makes it possible to effectively control the spatial environment of the city development [24]. One of the approaches to the reorganization process in the West is based on the elimination of industrial objects and architecture of residential and public buildings opposition.

Reconstruction (lat.) is a radical reorganization, improvement, streamlining of something. Reconstruction in architecture is the restructuring of the city, architectural complex, and buildings, caused by new living conditions [25].

Objects of reconstruction in the field of industrial architecture can be the following: industrial zone of the city, including all industrial areas and individual enterprises; industrial area (node); industrial enterprise; separate functional zones of an industrial enterprise (pre-factory, warehouse, engineering structures, etc.); industrial building; interior production workshop. The named objects correspond to different levels of the spatial industrial production organization.

In modern practice, the reconstruction of industrial facilities uses a number of concepts that reflect either individual aspects of the reconstruction process or specific approaches to carrying out reconstructive measures. These include technical re-equipment - updating and qualitative improvement of the technological equipment characteristics [26].

Technical re-equipment includes a set of measures to improve the technical and economic level of individual technological processes, replace the worn-out equipment of the main production and auxiliary services.

At the same time, not only the replacement of outdated equipment, machine tools, machines and mechanisms often occurs, but also the introduction of new promising technologies. When carrying out activities of architectural and construction industrial facilities reconstruction, it is also expected to replace outdated equipment and introduce new equipment, but, as a rule, to a lesser extent and with preservation of the existing technological process.

Therefore, in the process of reconstruction, various specific weight of the reorganization of the active and passive parts of the basic production assets is applied. The active part of the production assets includes machines and equipment, whereas the passive part includes factory territory with industrial buildings and structures. Reconstruction, first of all, involves the restructuring of existing cost-effective facilities the functioning of which is budget-forming for the city and provides a large number of jobs. In order to humanize the production environment, such facilities should provide for the reconstruction of industrial areas with the ergonomic spaces creation for recreation (short rest) and improvement of environmental and aesthetic environment indicators. Humanization methods of industrial areas should be carried out, first of all, taking into account the analysis of the production impact on the environment and the development of the most effective measures to reduce negative factors (harmful gases into the atmosphere, dust, odors, noise propagation, etc.).

The restoration is used to improve the aesthetic characteristics of the production environment. Basically, the restoration of facades is carried out, if the architecture of 
industrial buildings is of historical value and is an architectural monument.

Adaptation is the reorganization of an industrial facility for its use with a partial change in the functional process.
Regarding to industrial buildings or complexes, measures are proposed with the placement of a technological process related to another industry, as a rule, with less environmental stress on the environment [19].

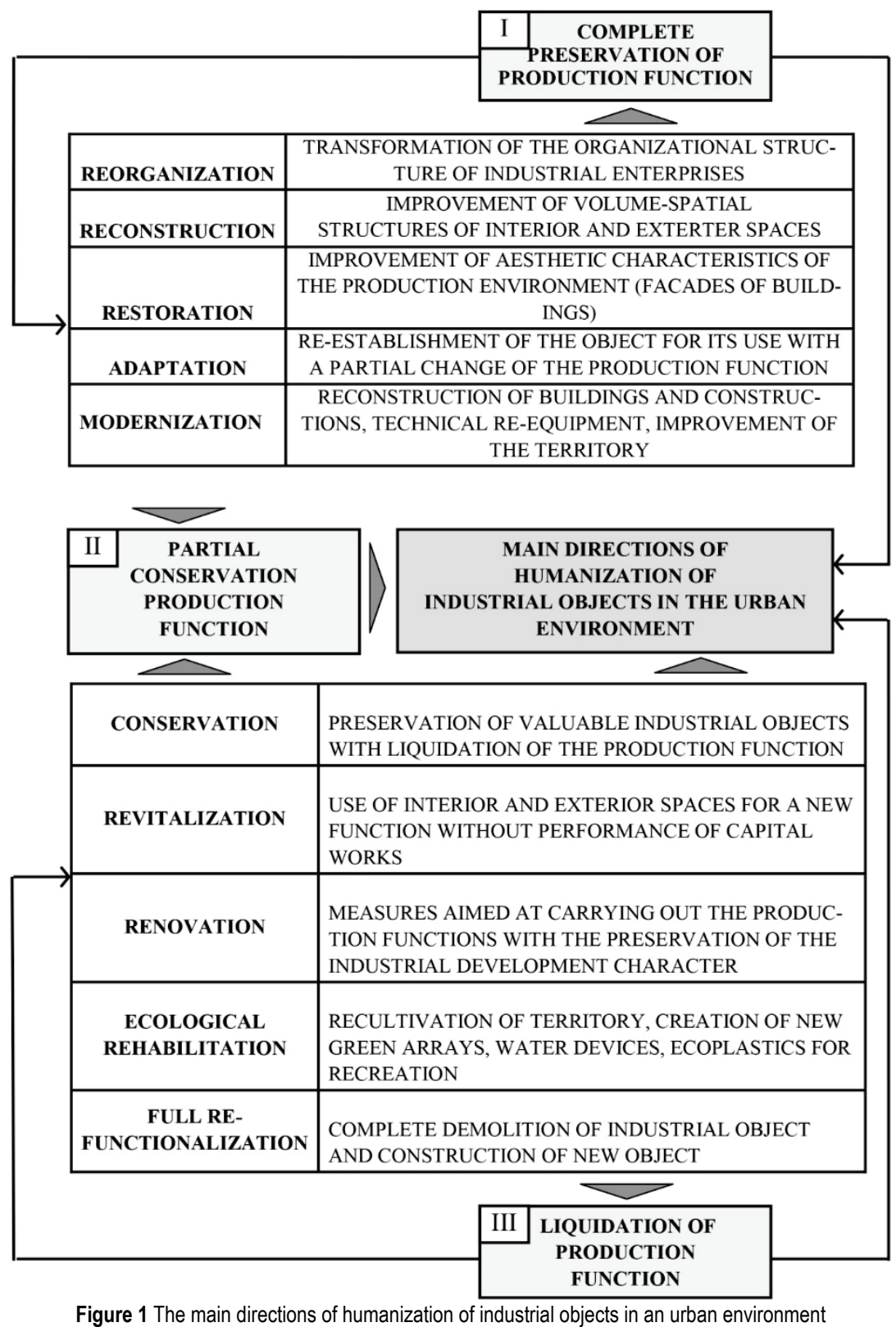

Complete modernization of the existing manufacture (refers to high-tech and environmentally ecological production) is reconstruction of buildings and structures, technical re-equipment, landscaping, more efficient use of available space with the introduction of modern technologies. Though this approach, the city does not lose the taxpayer (the company and the place of employment of citizens).

The second method of converting industrial facilities with partial preservation of the production function is most effective. This technique is appropriate in the socio-cultural terms, as it allows saving the production function and at the same time improving the aesthetic characteristics of the environment by combining the production function of the object and the function of the city. In this case, incomplete re-functionalization allows expanding the social infrastructure of the city and transforming the industrial territory to consider the new requirements.

A part of the industrial area with appropriate architectural and landscape transformations can be used to change the function. This part of the territory can be used for museum, recreational, residential and other functions. Thus, manufacture remains, but the industrial territory receives a new urban development. 
The third method of converting industrial facilities with a complete change of production functions is carried out in the process of conservation, revitalization, renovation, environmental rehabilitation, and complete refunctionalization.

Preservation and industrial archaeology are activities that include cultural and historical aspects aimed at the research and preservation of industrial objects that are part of the world material culture. Industrial archaeology is the identification, certification and research of monuments of industrial architecture and technology, the development of proposals for their safety and functioning. In the world practice, monuments of material culture after holding the relevant events function as museum recreational complexes, administrative, exhibition, trade and other objects.

Revitalization is the revival of urban space in which an industrial facility exists. Depending on the urban parameters of the object, this may be the space of the pre-plant zone, the street, the embankment, an industrial facility, a city block with industrial buildings or an industrial area. International practice has shown that it is revitalization that makes it possible to find new, more efficient and cost-effective ways of transforming former industrial facilities. Revitalization requires significantly smaller investments in contrast to renovation (redevelopment) with large-scale changes to the facility and significant investments. The lack of capital works makes it possible to noticeably shorten the period from the start of work on revitalization to the commissioning of a facility with a slightly updated interior and exterior environment. In addition, revitalization allows solving social and cultural problems, landscaping the territory, preserving the monuments of industrial architecture, reducing the load on the environment and improving the image of the city.

Renovation is a set of measures aimed at changing the functional purpose of an industrial facility. Renovation is a collective concept. Renovation is a transformation of an architectural object in which special zones of stability of the architectural space in an urban environment are created on the basis of taking into account psychological, historical, and aesthetic factors. This approach prevents the negative perception by consumers of the space of its significant changes when a separate industrial building, enterprise or district is transformed. Recently, conflict situations have arisen because of the people's personal attitude towards the architectural space where they live and work. Renovation allows solving the problem of continuity in the urban environment development.

Renovation as a method of humanization is usually used when changing the functional purpose of an industrial object. The industrial object environment often involves adjusting the existing urban planning environment. The renovation process should be understood as measures aimed at removing the production function while preserving the industrial nature of the building and recreating the new function. Inactive or inefficient production facilities, as well as industrial areas that impede the full further development of urban infrastructure, are subject to renovation.

Ecological rehabilitation, most often, involves the use of an industrial site for recreational purposes through the creation of parks, squares, a system of recreational avenues, etc. In the process of ecological rehabilitation, measures are taken to reclaim industrial areas that have fallen into the contaminated zone by returning the landscape to its original or close-to-original state. This process can be done by recreating the original natural components of the environment (soil, relief, vegetation, and water). In many cases, the professional use of landscape design allows to create a unique landscape environment with high emotional impact on the person.

Full re-functionalization is carried out on dilapidated industrial facilities. In this case, there is a complete demolition of dilapidated industrial facilities and the use of the territory for the new facility construction.

\section{CONCLUSIONS}

As a result of the research, the following conclusions were formulated:

1) In order to humanize the urban environment, it is necessary to improve the formation of industrial facilities and their territories while retaining the production function through reorganization, reconstruction, adaptation, and modernization. These activities will create a more comfortable environment for the work processes of human life and improve the ecological and aesthetic indicators of any city.

2) To improve the social and aesthetic characteristics of the urban environment and to humanize it, it is necessary to transform industrial facilities with a partial or complete change of the production function through conservation, revitalization, renovation, environmental rehabilitation, and complete re-functionalization.

The transformation of industrial facilities and their territories with a change in functionality becomes the main direction of the urban environment humanization in the $21^{\text {st }}$ century. Numerous architectural and compositional techniques allow adapting any industrial facility in the dynamic infrastructure of the city.

In further research, it is advisable to consider the main techniques for the formation of alternative objects in nonfunctioning industrial facilities.

\section{REFERENCES}

[1] Novikov, V. A. \& Ivanov, A. V. (1986). Architectural and aesthetic problems of reconstruction of industrial enterprises. Moscow: Stroiizdat, 168.

[2] Sedova, L. I. (2004). Fundamentals of compositional modeling in an architectural project: studies. allowance. Yekaterinburg: UralGAHA Publishing House, 29.

[3] Chaiko, D. S. (2007). Modern directions of integration of historical production facilities in the urban environment. Moscow: MARHI, 214.

[4] Agranovich, G. M. \& Mamleev, O. R. (1996). Reconstruction of industrial enterprises in the historical urban development. News of universities. Building, (1), 100-104.

[5] Vershinin, V. I. (2007). Evolution of industrial architecture. Moscow: Architecture-S, 210. 
[6] Demidov, S.V. \& Khrustalev, A. A. (Eds). (1984). Architectural design of industrial enterprises. Moscow: Stroiizdat, 392.

[7] Votinov, M. A. (2013). Prerequisites for the humanization of industrial territories in the largest cities of Ukraine. Kharkiv: KhNUMG im. O. M. Beketova, No. 112, 161-166.

[8] Avdotin, L. N., Lezhava, I. G., \& Smolyar, I. M. (2009). Urban planning: Textbook. For universities. St. Petersburg: Tekkniga, 432.

[9] Belousov, V. N. \& Kulaga L. N. (Eds). (1981). Basics of the formation of the architectural and artistic appearance of cities. Moscow: Stroiizdat, 192.

[10] Savarenskaya, T. F., Shvidkovsky, D. O., \& Petrov, F. A. (2006). History of urban development of art. Moscow: Architecture-S.

[11] Biryukov, L. E. (1978). Basics of planning and improvement of populated areas and industrial areas: studies. Manual for universities. Moscow: High School, 232.

[12] Daun, K. (2012). Humanivity - Innovative Economic Development through Human Growth. Books on Demand, 250.

[13] Sullivan, J. B. \& Krieger, G. R. (2001). Krieger Clinical Environmental Health and Toxic Exposures. - Lippincott Williams \& Wilkins, 1323.

[14] Voskresenskiy, I. N. (2004). Harmony and ecology: ways of integration. - Landscape architecture. Design, (3), 66-74.

[15] Côté, R., Tansey, J., \& Dale, A. (2007). Linking Industry and Ecology: A Question of Design. UBC Press, 288.

[16] Gibson, D. P., Hodgson, J. A., Schroeder, K. L., \& Spitzer, D. A. (2010). Navigating Municipal Environmental and Energy Issues: Municipal Law Experts on Meeting New Compliance Standards, Addressing Land Use and Redevelopment Concerns, and Prioritizing Environmental Policies (Inside the Minds). Aspatore Books. 92.

[17] Kim, A. N. N. (1979). Industrial architecture. Moscow: Stroiizdat, 176.

[18] Demidov, S. V. \& Khrustalev, A. A. (Eds). (1984). Architectural design of industrial enterprises. Moscow: Stroiizdat, 392.

[19] Getun, G. V. (2009). Fundamentals of the project of promislovy budivel: navch. ambassador. Kiev: Condor, 210.

[20] Semenova, I. V. (2009). Industrial ecology: study guide. Moscow: Academy, 528.

[21] Building Regulations. (1994). II-89-80. Master plans of industrial facilities. Moscow, 44.

[22] Philip, H. (2007). The human impact on biological diversity. How species adapt to urban challenges sheds light on evolution and provides clues about conservation. EMBO Rep. Apr. 8(4): 316-318. https://doi.org/10.1038/sj.embor.7400951

[23] Dyatkov, S. V. \& Mikheev, A. P. (2010). The architecture of industrial buildings: a textbook. Moscow: Architecture-S, 552.

[24] Smirnova, O. V. (2014). Loft as an innovative object for the formation of residential buildings. Kharkiv: KhNUMG im. O. M. Beketova, No. 118, 138-141.

[25] Sysoeva, O. (2005). Reconstruction of industrial facilities. Minsk: BNTU, 136

[26] Orange, H. (2016). Reanimating Industrial Spaces: Conducting Memory Work in Post-industrial Societies. Routledge, 254. https://doi.org/10.4324/9781315421179

[27] Hough, M. (2004). Cities and Natural Process: A Basis for Sustainability. Psychology Press, 292.

https://doi.org/10.4324/9780203643471

\section{Authors' contacts:}

Maksym Votinov, $\mathrm{PhD}$ in Architecture, Associate Professor Department of the Basics of Architectural Design, O. M. Beketov National University of Urban Economy in Kharkiv, 17, Marshal Bazhanov Street, Kharkiv, 61002, Ukraine E-mail: votinelly@ukr.net

Contact tel.: 096-761-89-16

Olga Smirnova, PhD in Architecture, Associate Professor Department of Architecture of Buildings and Structures and Design of Architectural Environment,

O. M. Beketov National University of Urban Economy in Kharkiv, 17, Marshal Bazhanov Street, Kharkiv, 61002, Ukraine

E-mail: 0.l-y.a@mail.ru

Contact tel.: 098-05-99-157

Maria Liubchenko, PhD in Technical Science, Associate Professor Department of the Basics of Architectural Design,

O. M. Beketov National University of Urban Economy in Kharkiv,

17, Marshal Bazhanov Street, Kharkiv, 61002, Ukraine

E-mail: mariialiu@gmail.com

Contact tel.: 098-281-34-42 